\title{
Avaliação, análise e desenvolvimento de jogo sério digital para desktop sobre sintomas e procedimentos de emergência do Acidente Vascular Cerebral Evaluation, analysis and development of desktop digital serious game on symptoms and emergency procedures of stroke
}

\author{
Carlos Felippe Dias Limeira, José Guilherme Santa Rosa, André Luís Santos de Pinho
}

design, jogo sério digital, design centrado no usuário, acidente vascular cerebral

O presente artigo apresenta parte do resultado de uma pesquisa de mestrado e busca demonstrar que 0 uso de um jogo sério digital pode facilitar o processo de ensino-aprendizagem de pré-adolescentes acerca dos sintomas e procedimentos de emergência do Acidente Vascular Cerebral (AVC), partindo da hipótese de que na transmissão de informações sobre os sintomas do AVC e do número do SAMU (Serviço Ambulatório Móvel de Urgência) a utilização de um jogo sério digital pode ser mais eficaz no que se refere à preferência e retenção das informações apresentadas do que uma animação digital desenvolvida com a mesma finalidade. A metodologia adotada visou à coleta e análise de dados qualitativos e quantitativos, a partir de instrumentos metodológicos adaptados dos já existentes na literatura (prototipagem de jogo digital, entrevista semiestruturada, escala visual de humor Pick-A-Mood, grupo focal) e desenvolvidos exclusivamente para a pesquisa (teste de retenção com "dedoches" e teste de preferência). Concluiu-se que embora não houve diferenças significativas entre a retenção do número do SAMU ao comparar o jogo com a animação, o jogo sério digital demonstrou ser mais eficaz na retenção dos sintomas do AVC e na preferência dos pré-adolescentes.

design, digital serious game, user-centered design, stroke

This article presents part of the result of a master's research and seeks to show that the use of a digital serious game can ease the process of teaching and learning pre-teens about the symptoms and emergency procedures of stroke, based on the following hypothesis that the transmission of information on the symptoms of stroke and ambulance number using a digital serious game can be more effective with regard to preference and retention of information presented than a digital animation developed for the same purpose. The methodology seeked to collect and analyze qualitative and quantitative data from adapted methodological tools existing in the literature (digital game prototyping, semi-structured interviews, visual scale of humor Pick-A-Mood, focus group) and developed exclusively for the search (retention test fingerpuppet and preference test). It was concluded that although there were no significant differences between the retention of ambulance number to compare the game with animation, digital serious game was more effective in retaining symptoms of stroke and preference for pre-teens.

\section{Introdução}

Nos últimos anos, as constantes transformações impulsionadas pelo desenvolvimento das tecnologias digitais trouxeram significativas mudanças nos mais diversos campos da sociedade.

C. F. D. Limeira, J. G. S. Rosa, A. L. Santos de Pinho. 2015. Avaliação, análise e desenvolvimento de jogo sério digital para desktop sobre sintomas e procedimentos de emergência do Acidente Vascular Cerebral. In: C. G. Spinillo; L. M. Fadel; V. T. Souto; T. B. P. Silva \& R. J. Camara (Eds). Anais [Oral] do $7^{\circ}$ Congresso Internacional de Design da Informação/Proceedings [Oral] of the 7th Information Design International Conference | CIDI 2015 [Blucher Design Proceedings, num.2, vol.2]. São Paulo: Blucher, 2015. ISSN 2318-6968, DOI 10.5151/designpro-CIDI2015-cidi_190 
$\mathrm{Na}$ educação, o uso das tecnologias digitais possibilitou novas formas de aprendizagem, levando a uma aproximação da escola com as linguagens midiáticas já pertencentes ao cotidiano dos alunos. Um exemplo disto é o uso de jogos digitais com fins educativos, como os denominados jogos sérios, que combinam tecnologias e conceitos de jogo com estratégias pedagógicas que visam contribuir para a construção de saberes nas mais diversas áreas do conhecimento humano.

$\mathrm{Na}$ área da Educação em Saúde, todos os anos são realizadas campanhas educativas de combate ao Acidente Vascular Cerebral (AVC) pelo mundo, visando sensibilizar a população acerca da doença, seus sintomas e procedimentos de emergência. Voltadas à educação popular, as campanhas de combate ao AVC fazem uso de instrumentos como cartilhas impressas, páginas na Internet e vídeos digitais. Nesse cenário em que tecnologia torna-se forte aliada do processo educativo, torna-se necessário adequar o uso das ferramentas de forma contextualizada com o grupo sociocultural a que se destina.

Uma possibilidade destacada é o uso de jogos sérios digitais pelo público jovem, visto sua popularidade e aceitação por crianças e adolescentes, despertando um maior interesse e sensibilidade pelo conteúdo abordado e assim causando um comportamento multiplicador entre os jovens (Santa Rosa et al., 2014).

Esse trabalho apresenta parte do resultado de uma pesquisa de mestrado desenvolvida no programa de pós-graduação em Design pela Universidade Federal do Rio Grande do Norte (UFRN), tendo como área de concentração o Ergodesign e linha de pesquisa Interação HumanoComputador e Ergonomia Informacional. O presente artigo apresenta uma reflexão sobre o uso de jogos digitais no contexto educacional, aliando os princípios do game design com a abordagem do Design Centrado no Usuário, assim como o desenvolvimento e a avaliação de um jogo sério digital sobre sintomas do AVC e procedimentos de emergência voltados a estudantes pré-adolescentes, na faixa etária de 8 a 12 anos, buscando compreender sua eficácia pedagógica na preferência e retenção dos conhecimentos apresentados se comparado a uma animação digital de mesma finalidade.

\section{Jogos digitais e educação}

Os jogos são sistemas complexos projetados para suportar as ações dos jogadores e gerar respostas significativas por meio da interação, possuindo um forte componente motivacional e sendo causadores de engajamento social. Ao participar dessa brincadeira organizada, o jogador se submete às limitações impostas pelas regras para atingir os objetivos traçados pelo jogo, enfrentando obstáculos em um nível de dificuldade progressiva e sendo gratificado por meio de recompensas (Salen e Zimmerman, 2012).

Para Schell (2008) o poder exercido pelos jogos reside numa combinação de quatro elementos fundamentais que os constituem: a mecânica (procedimentos e regras do jogo), a narrativa (história apresentada sob a forma de eventos em sequência), a estética (elementos visuais, sonoros, táteis e cinestésicos) e a tecnologia (materiais e interações que tornam o jogo possível).

Fenômenos da cultura contemporânea e geralmente relacionados ao lazer, os jogos digitais são causadores de impactos psíquicos, culturais, científicos e educacionais (Venturelli e Maciel, 2008) e tornam-se atrativos para o público jovem, principalmente pelo seu caráter interativo e pela presença e dinamismo dos elementos visuais (Greenfield, 1988). A interatividade não é uma característica exclusiva dos jogos digitais, mas a qualidade de sua interação destacase pela sensação de imersão experimentada pelo jogador neste meio (Xavier, 2010; Portugal, 2013).

A experiência imersiva proporcionada pelos games é relacionada ao estado de fluxo

Anais [Oral] do 7º Congresso Internacional de Design da Informação | CIDI 2015

Proceedings [Oral] of the 7th Information Design International Conference / IDIC 2015 
(flow), um estado de total imersão que alcançamos em determinadas atividades que exigem mais energia, concentração e atenção, dos quais obtemos respostas e recompensas, através de desafios apresentados de forma progressiva e compatíveis com as nossas habilidades (Csikszentmihalyi, 1999).

Os jogos digitais, desenvolvidos ou não para fins educativos, envolvem processos de aprendizagem e construção de saberes (Mendes, 2006; Albuquerque e Fialho, 2009), podendo atuar como facilitadores para a aquisição de certos conteúdos e habilidades (Magnani, 2008). Dessa forma, alguns tipos de jogos podem possibilitar um aprendizado ativo, favorecendo a descoberta e o desafio, fatores importantes para o processo educacional. Para Battaiola (2000) o que diferencia os jogos educacionais dos demais jogos são os critérios didático-pedagógicos associados aos conceitos que serão difundidos no jogo.

No estágio atual em que a transmissão de conhecimentos acontece dentro e fora dos espaços formais acadêmicos, os jogos digitais apresentam-se como uma importante ferramenta educacional de apoio ao ensino (Lévy, 1999). Atualmente, para muitos alunos as atividades escolares não se constituem como atividades prazerosas (Csikszentmihalyi e Hunter, 2003) e diante da entrada massiva das tecnologias digitais no cotidiano, torna-se necessário repensar a relação das mídias digitais com o processo de ensino-aprendizagem, de modo a proporcionarem uma aprendizagem significativa.

Desenvolvidos com o objetivo de cumprir fins pedagógicos, os jogos sérios (serious game) exploram o poder motivacional e envolvente dos jogos no processo de construção de saberes. O desafio dos jogos educacionais é equilibrar os desafios lúdicos e os conteúdos didáticos,sem esquecer o fator diversão comum aos jogos de entretenimento (Yue e Zin, 2009). No desenvolvimento de jogos sérios, a estrutura do jogo deve adequar-se ao conteúdo pedagógico (Costa, 2010), contemplando elementos universais que fazem os jogos de entretenimento serem atrativos (Battaiola et al., 2002).

A produção de jogos sérios digitais é uma busca natural dos educadores por recursos que facilitem o diálogo com o público jovem, contextualizando os conteúdos em situações práticas de desafio virtual (Timm et al., 2008) a partir de intenções pedagógicas definidas (Ribeiro et al., 2006). Para Portugal (2013) existe no campo do design um grande potencial para trabalhos conjuntos com a área da Educação, com vistas a atender as novas exigências da sociedade contemporânea. Segundo a supracitada autora, tecnologias digitais aplicadas à educação, como os games, propõem perspectivas de ensino inovadoras, enriquecendo o processo de ensino-aprendizagem com o desenvolvimento de ambientes educacionais a partir de um olhar múltiplo e inclusivo.

\section{Game Design centrado no usuário}

O game design é um campo multidisciplinar com contribuições de diversas áreas do conhecimento, que tem como principal meta proporcionar experiências significativas para os jogadores, projetando o contexto, elementos e regras do jogo experimentados por meio da jogabilidade. Trata-se de um processo iterativo no qual as decisões de design são tomadas a partir da observação da experiência do jogar, utilizando-se da prototipagem e testes de jogabilidade (playtest) com o público-alvo do jogo (Salen e Zimmerman, 2012).

O desenvolvimento de jogos educativos requer uma equipe multidisciplinar de trabalho, com a presença de especialistas da área da educação (Bates, 2004), trabalhando de forma conjunta para assegurar a qualidade e cumprimento dos objetivos educacionais pretendidos. Torna-se imprescindível também, a inclusão dos próprios usuários dentro do processo de design participando de forma ativa no levantamento de requisitos e das etapas de avaliação dos protótipos até a versão final do jogo.

O foco e a inclusão dos próprios usuários no processo de game design vai de encontro

Anais [Oral] do $7^{\circ}$ Congresso Internacional de Design da Informação | CIDI 2015

Proceedings [Oral] of the 7th Information Design International Conference / IDIC 2015 
aos objetivos do Design Centrado Usuário (DCU), uma abordagem do design de produtos ou sistemas com foco nas questões relativas ao usuário, utilizando métodos e técnicas que visam contemplar suas necessidades (Rubin, 1994). Segundo Santa Rosa e Moraes (2012) o DCU diz respeito ao envolvimento dos usuários durante a fase de projetação, em momentos específicos como nas etapas de avaliação e testes com protótipos, no emprego de métodos qualitativos para observar o comportamento, medir satisfação, aceitação e facilidade de uso dos usuários com determinados artefatos, posicionando o usuário como centro do processo e considerando aspectos físicos, cognitivos, emocionais e ambientais ao projetar ou redesenhar um sistema/produto.

A entrada das tecnologias digitais na área da educação modificou as relações no processo de ensino, trazendo a necessidade do estudo e exploração de novos suportes e recursos auxiliares ao aprendizado. Alves e Battaiola (2014) relacionam a abordagem do Design Centrado no Usuário e as novas concepções pedagógicas, em que o DCU pode contribuir para o desenvolvimento de tecnologias educacionais que promovam a aprendizagem significativa por possibilitar a compreensão das necessidades e do contexto do aprendiz.

Apesar de existirem diversos modelos de análise ergonômica e da usabilidade de jogos digitais, a avaliação empírica por usuários se faz indispensável, com o objetivo de compreender sua interação e experiência (Alves e Padovani, 2006). Os métodos de investigação direta com usuários de jogos digitais (também conhecidos por testes de jogabilidade), geram dados qualitativos obtidos por meio de entrevistas, observações, questionários e investigação direta, que deverão enriquecer e complementar os dados quantitativos obtidos (Yue e Zin, 2009).

\section{Metodologia}

O presente artigo apresenta parte do resultado de uma pesquisa de mestrado acerca do uso de jogos sérios digitais na área da Educação em Saúde. A discussão empreendida neste artigo parte do princípio de que o uso de um jogo sério digital pode atrair a atenção e facilitar o processo de aprendizagem de jovens pré-adolescentes acerca do Acidente Vascular Cerebral (AVC), já que os materiais educativos desenvolvidos para campanhas educativas de combate a doença, como cartilhas e vídeos animados, nem sempre são muito atrativos e eficazes com o público mais jovem, tornando-se necessário, portanto, desenvolver estratégias pedagógicas que utilizem as tecnologias de forma contextualizada com o público-alvo a qual se destinam.

A hipótese a ser verificada é que na transmissão de informações sobre os sintomas do AVC e do número do SAMU (Serviço Ambulatório Móvel de Urgência) a utilização de um jogo sério digital pode ser mais eficaz no que se refere à preferência e retenção das informações apresentadas do que uma animação digital desenvolvida com a mesma finalidade e utilizada em campanhas educativas nacionais de combate ao AVC.

Para tanto, apresentamos uma reflexão sobre o uso de jogos digitais no contexto educacional, buscando demonstrar que a utilização de um jogo sério digital, desenvolvido ao se aliar os princípios do game design com a abordagem do Design Centrado no Usuário, pode facilitar o processo de ensino-aprendizagem de pré-adolescentes acerca dos temas destacados.

A animação digital ${ }^{1}$ utilizada foi realizada pela Sociedade Brasileira de Doenças Cerebrovasculares (SBDC) e utilizada em campanhas nacionais de combate ao AVC. Com duração aproximada de três minutos, a animação apresenta um personagem (garoto) que diagnostica outros (idoso, idosa e adulto) com diferentes sintomas do AVC (boca torta, braço fraco e fala embolada), ensinando a acionar na estória o número 192 do SAMU a partir de um telefone celular.

\section{O jogo digital para desktop utilizado foi desenvolvido pelo Laboratório de Ergodesign de}

\footnotetext{
${ }^{1}$ Disponível em < http://youtu.be/SNYwW8vxMDg >.

Anais [Oral] do 7º Congresso Internacional de Design da Informação | CIDI 2015

Proceedings [Oral] of the 7th Information Design International Conference / IDIC 2015
} 
Interfaces, Experiência do Usuário e Usabilidade (LEXUS/UFRN) e intitula-se "Esquadrão 192". Nele, o jogador controla o avatar do personagem principal ("Agente X") que deverá identificar e diagnosticar outros personagens com sintomas do AVC, acionando ajuda médica por um celular virtual. Os elementos audiovisuais foram desenvolvidos pela equipe e o roteiro elaborado sob a supervisão de especialistas em Educação. A mecânica básica de jogo consiste em desviar de obstáculos colocados propositalmente no caminho do personagem avatar do jogador durante a partida. A tecnologia utilizada (motor de jogo ou engine) foi o Scirra® Construct 2.

$\mathrm{Na}$ presente pesquisa, foram utilizadas duas versões do jogo para as etapas de avaliação: (i) protótipo horizontal de alta fidelidade ${ }^{2}$, desenvolvido no período entre janeiro e março de 2014; e (ii) versão beta $^{3}$, desenvolvida entre agosto e novembro de 2014, que pôde contemplar as sugestões de melhoria oriundas da etapa de avaliação do protótipo com o públicoalvo do jogo. Participaram das etapas de avaliação com os objetos da pesquisa (animação e jogo digital), 43 estudantes pré-adolescentes (entre 8 e 12 anos) da Escola Municipal Juvenal Lamartine, localizada na cidade de Natal (RN), após autorização dos pais e responsáveis via assinatura do Termo de Consentimento Livre e Esclarecido (TCLE).

A metodologia adotada contemplou a coleta e análise de dados qualitativos e quantitativos, a partir de instrumentos metodológicos adaptados dos já existentes na literatura (prototipagem de jogo digital, entrevista semiestruturada, escala visual de humor Pick-A-Mood, grupo focal) e desenvolvidos exclusivamente para a pesquisa (teste de retenção com "dedoches" e teste de preferência), sempre buscando adequá-los aos sujeitos da pesquisa, de modo a poderem ser aplicados de forma rápida e lúdica, auxiliando na compreensão e investigação da experiência dos pré-adolescentes com a animação e o jogo sério digital.

\section{Etapas e instrumentos de avaliação dos objetos da pesquisa}

As etapas de avaliação dos objetos com os sujeitos da pesquisa aconteceram em duas fases distintas: (i) avaliação da animação e protótipo do jogo sério digital, realizada entre 26 de março a 11 de abril de 2014; e (ii) avaliação da animação e beta do jogo sério digital, realizada entre 17 de novembro a 12 de dezembro de 2014. Entre ambas as etapas, ou seja, logo após a realização da etapa de avaliação com protótipo do jogo, ocorreu a fase de desenvolvimento da versão beta do jogo sério digital, que por sua vez, também foi avaliada.

A realização das etapas de avaliação com o jogo sério digital "Esquadrão 192" e seu público-alvo, formado por pré-adolescentes, buscou verificar se os parâmetros de jogo estavam adequados às expectativas e objetivos dos desenvolvedores e usuários. Testes pilotos foram realizados com o objetivo de aperfeiçoar os instrumentos e procedimentos adotados.

Cada etapa de avaliação foi realizada em dois dias, com um intervalo de um dia (24 horas) entre ambos. Os critérios de escolha dos participantes foram: ausência de limitações físicas e/ou cognitivas que poderiam impedir a interação dos sujeitos; e sujeitos que ainda não tenham participado da pesquisa.

Com o objetivo de melhor avaliar a experiência dos participantes em contextos específicos, estes foram inseridos em grupos e cada um associado a um código numérico, a fim de manter a confidencialidade dos sujeitos da pesquisa:

- Grupo 1 (Animação) em que os participantes assistiram ao desenho animado;

- Grupo 2 (Animação e Jogo) com os participantes submetidos à animação e ao jogo sério digital (nesta ordem);

\footnotetext{
${ }^{2}$ Disponível em: < http://www.esquadrao192.com.br/prototipo >.

${ }^{3}$ Disponível em: < http://www.esquadrao192.com.br >.
}

Anais [Oral] do 7º Congresso Internacional de Design da Informação | CIDI 2015 
- Grupo 3 (Jogo e Animação) com os participantes submetidos ao jogo sério e à animação digital (nesta ordem);

- Grupo 4 (Jogo) em que os participantes interagiram com o jogo.

Figura 1: Fluxograma com as etapas de avaliação dos objetos da

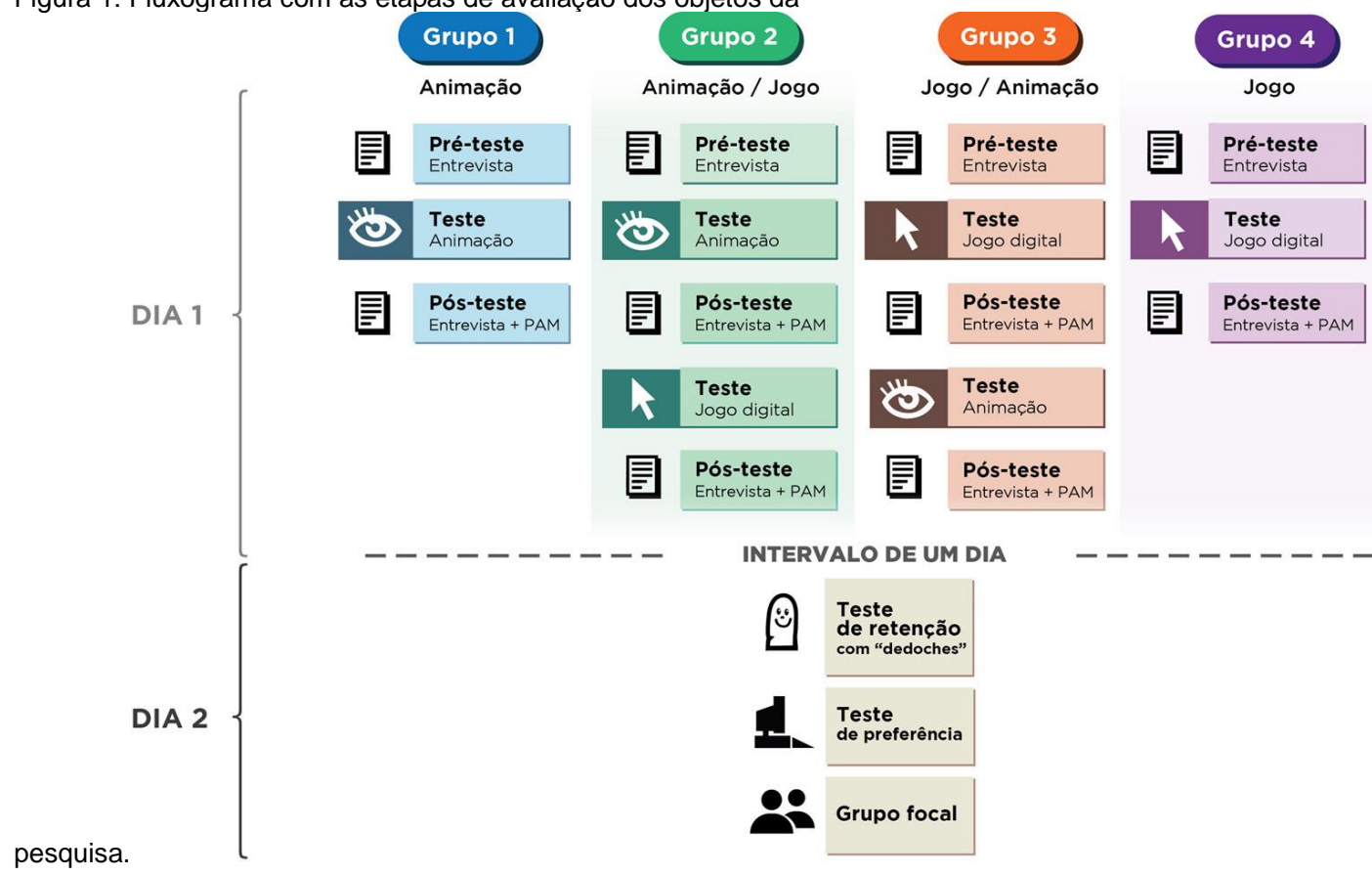

Destaca-se que na etapa de avaliação com protótipo do jogo, os sujeitos da pesquisa foram inseridos nos grupos 1, 2 e 3, sendo o grupo 4 criado apenas na etapa de avaliação com beta do jogo sério digital. No grupo 4 o objetivo era de extrair informações mais detalhadas acerca da interação do sujeito com o jogo.

\section{Pré-teste}

Com o objetivo de extrair informações do contexto sociocultural dos pré-adolescentes e compreender os seus conhecimentos acerca dos temas abordados, foi realizado o pré-teste, etapa em que os participantes puderam responder de forma oral perguntas elaboradas a partir de um roteiro.

1. Você costuma ver desenhos animados (Se sim, quais)?

2. Você costuma jogar jogos digitais (Se sim, quais jogos e em quais dispositivos)?

3. Você sabe ligar de um telefone celular?

4. Você sabe o que é o Acidente Vascular Cerebral (Se sim, quais os sintomas)?

5. Você sabe o que é o SAMU (Se sim, qual o número)?

Figura 2: Entrevista com sujeito durante pré-teste (A) a partir de roteiro elaborado (B). 


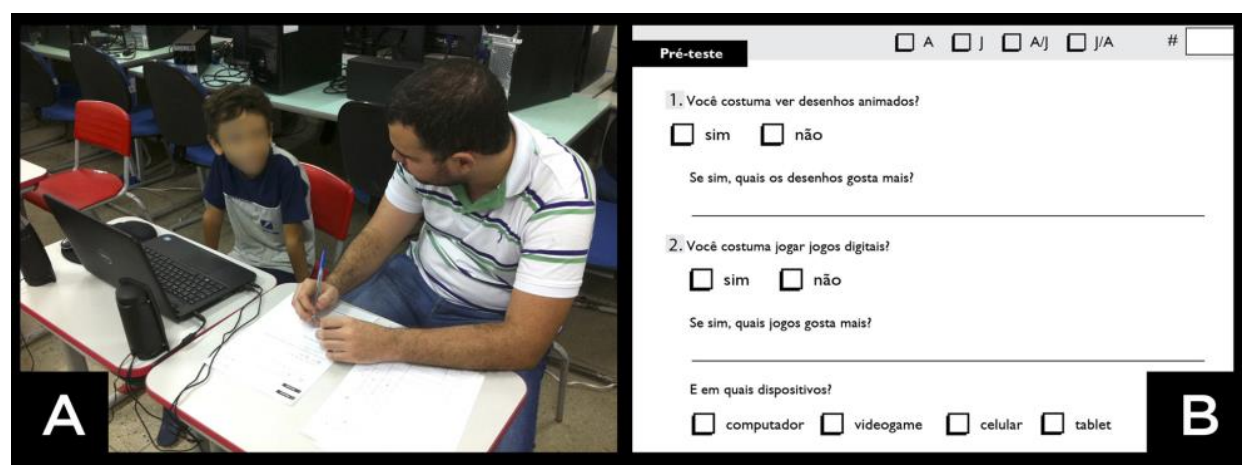

\section{Teste com animação e jogo}

Após o pré-teste, os participantes foram apresentados e puderam interagir com os objetos da pesquisa (animação e jogo), de acordo com um dos grupos nos quais foram inseridos. Observou-se o comportamento dos sujeitos enquanto assistiam a animação e interagiam com o jogo sério digital. Durante a interação com o jogo, o pesquisador apenas interferiu quando realmente houve necessidade a fim de ajudar ou esclarecer alguma dúvida ou situação enfrentada pelo participante.

Figura 3: Sujeitos assistindo a animação (A) e interagindo com o jogo (B).

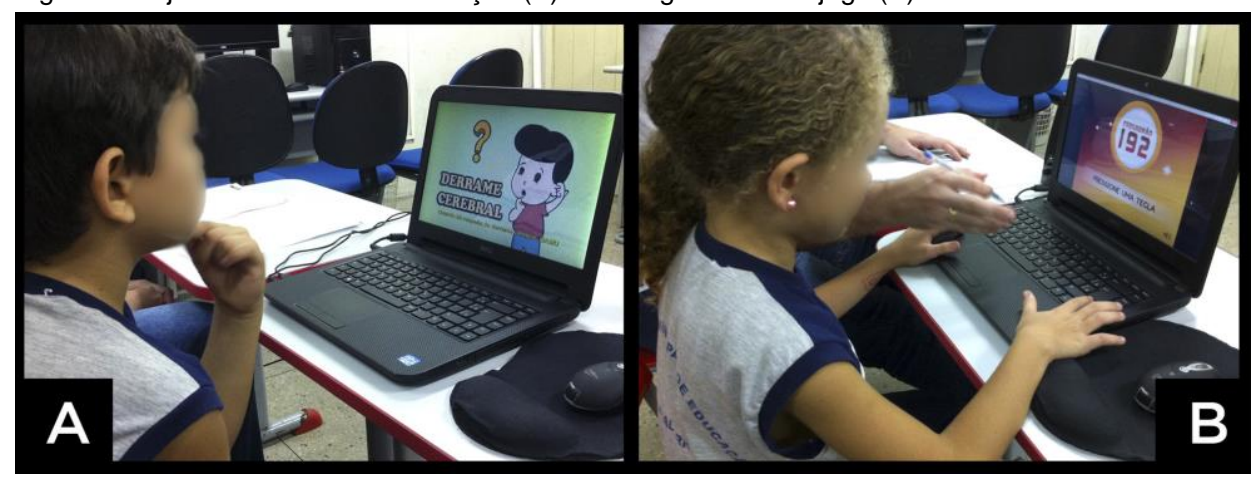

\section{Pós-teste}

Após a interação dos sujeitos com os objetos da pesquisa foi realizado o pós-teste, em que cada um relatou a sua experiência com a(s) respectiva(s) mídia(s), avaliando o seu humor através do uso da escala visual Pick-A-Mood (PAM), para depois responder oralmente as perguntas:

1. Você gostou? Por quê?

1.1. Assistiria ou jogaria novamente?

1.2. Qual gostou mais? (no caso do participante que interagiu com ambas as mídias, animação e jogo);

2. Você lembra de algum dos sintomas do AVC que aparecem na animação/jogo? 2.1. Se sim qual(is) sintoma(s)?

3. Você sabe o número do SAMU?
3.1. Se sim, qual o número?

Figura 4: Pós-teste utilizando a escala visual Pick-A-Mood (A) com o personagem robô (B). 


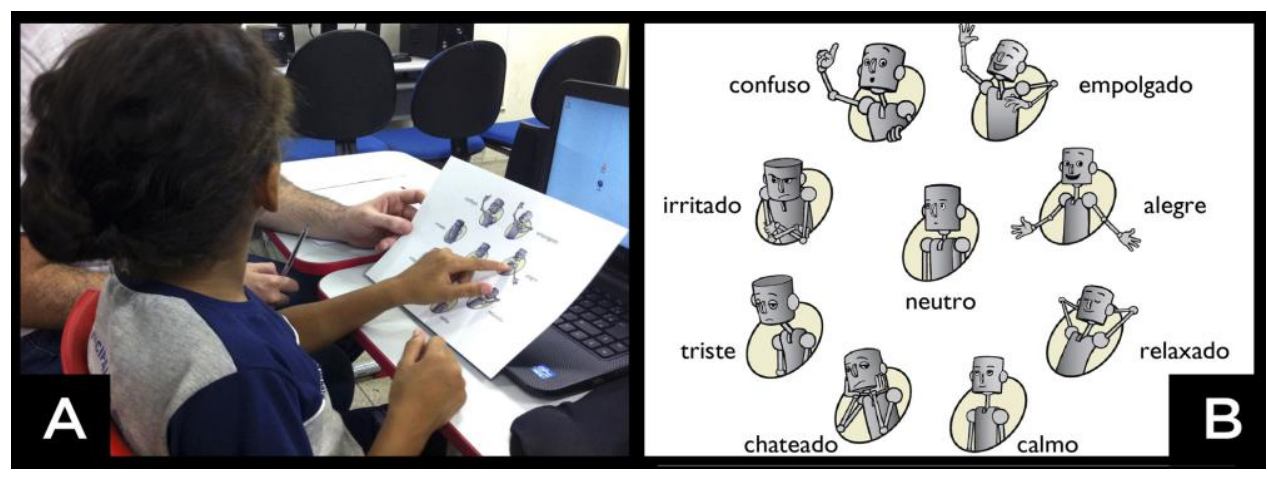

A adoção de um instrumento de medição de humor se deu por dois motivos: (i) a compreensão do humor é relevante em projetos de design, na compreensão da experiência com produtos e ambientes; e (ii) o uso de uma escala visual com as expressões de personagens animados possibilita aos participantes relatarem o seu humor de forma mais rápida e intuitiva (Desmet et al., 2012).

\section{Teste de retenção}

Após o intervalo de um dia (24 horas), no segundo dia da etapa de avaliação, ocorreu o teste de retenção, que teve como propósito medir o nível de retenção das informações transmitidas anteriormente através do jogo e da animação digital, de uma forma mais lúdica e interativa. Para isso foi desenvolvida e encenada a apresentação de um teatro de bonecos de dedo "dedoches", em que os sujeitos puderam interagir com os mesmos personagens apresentados no jogo.

Figura 5: Teste de retenção com dedoches.

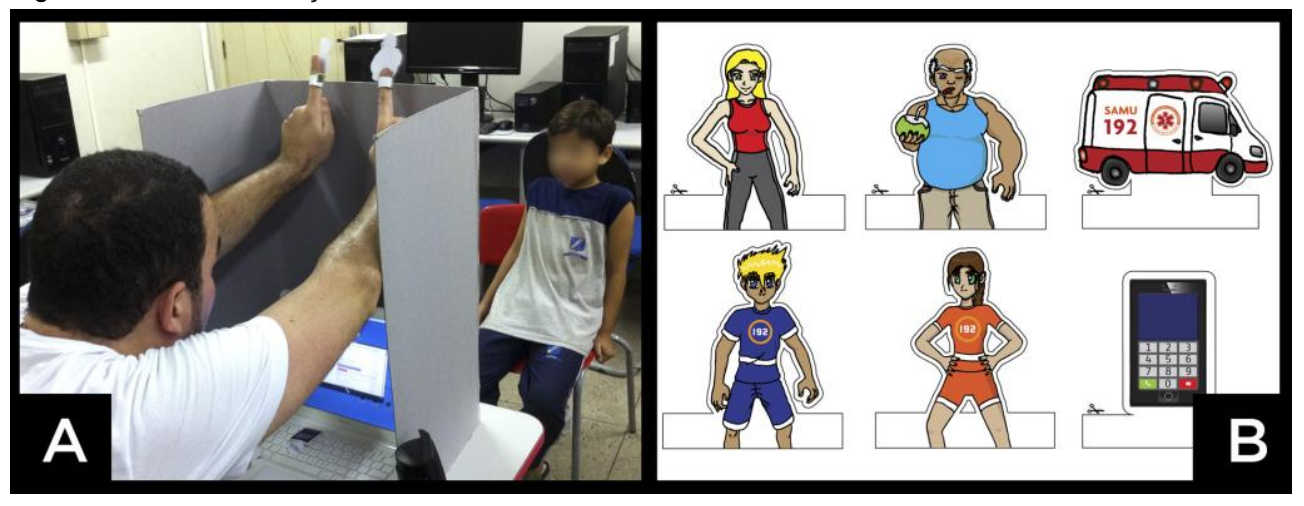

\section{Teste de preferência}

Após o teste de retenção com o uso dos "dedoches", ocorreu o teste de preferência, que consistiu na observação do comportamento em grupo dos participantes a partir da disponibilização de dois computadores desktop, sendo um apresentando o jogo sério e outro a animação digital. Os pesquisadores deixaram os pré-adolescentes livres por aproximadamente dez minutos e observaram sua preferência a respeito dos dois recursos apresentados, bem como os comentários e diálogos a respeito. A realização desta etapa também teve como finalidade deixar os participantes mais à vontade antes da realização da atividade posterior (grupo focal) e ao mesmo tempo propiciar mais um contato com os recursos, já que nem todos os sujeitos puderam assistir e jogar durante as entrevistas individuais, devido a inclusão de alguns sujeitos em grupos (grupos 1 e 4 ) que tiveram contato com apenas um dos recursos (animação ou jogo). 
Figura 6: Teste de preferência.

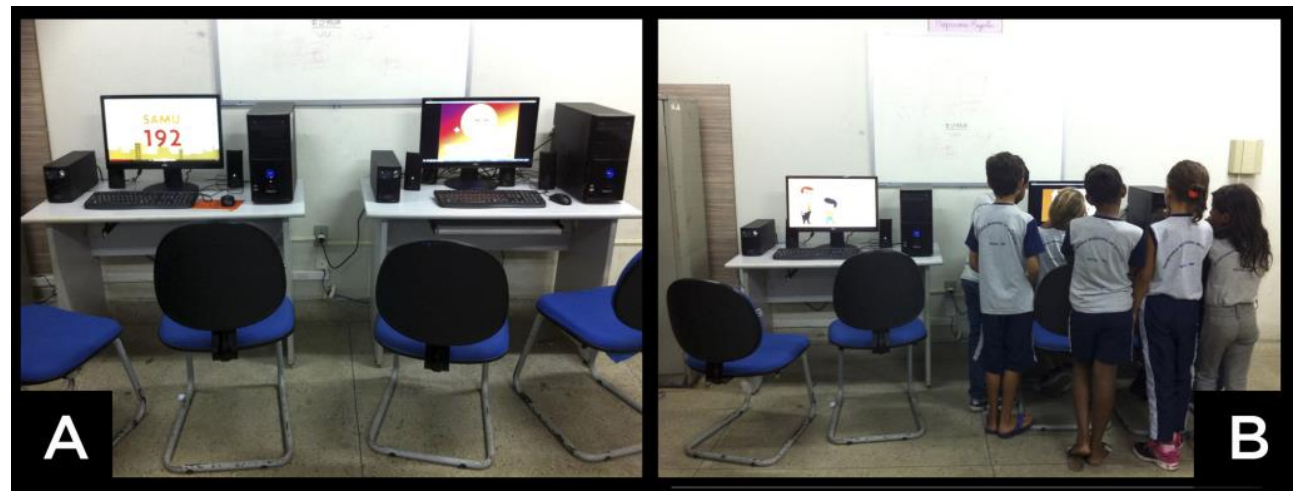

\section{Grupo Focal}

Em seguida, logo após o teste de retenção realizou-se o grupo focal, uma entrevista feita em grupo com o objetivo de levantar considerações mais aprofundadas e sugestões de melhoria para o jogo pelos participantes.

A adoção do uso desta alternativa metodológica na presente pesquisa teve o objetivo de extrair opiniões e demais sugestões dos participantes reunidos de forma coletiva, acerca de determinados pontos dos objetos apresentados (jogo e animação digital), focalizando quais aspectos foram mais atrativos para o grupo e por quê.

A escolha do ambiente, materiais e procedimentos adotados procurou seguir as orientações de aplicação da técnica grupo focal (também chamada por grupo de foco), trazidas pela literatura sobre o tema, com a condução da sessão pelo moderador a partir de um roteiro previamente desenvolvido:

1. Qual dos dois foi mais interessante? Por quê?

2. O que o desenho tem de legal? (desenhos, cor, música etc.);

3. O que o jogo tem de legal? (personagens, cenário, música, vozes, cenas animadas, fases, discagem, fase da ambulância, encerramento etc);

4. Os personagens são bonitos? (comparar desenho com jogo);

5. A música do jogo é legal? (comparar desenho com jogo);

6. Como o jogo poderia ser melhorado? (seria mais legal se tivesse...);

7. Se pudéssemos inventar outro jogo como seria? (que tipo de jogo, personagens, cenários, músicas etc.).

Figura 7: Grupo Focal. 


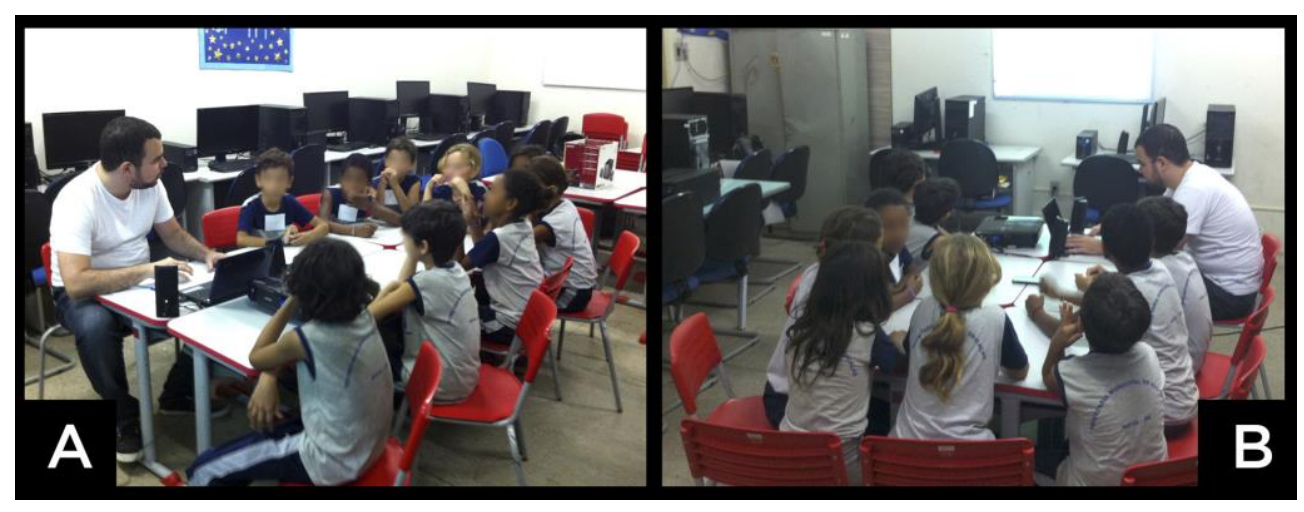

Destaca-se também que, para a realização desta etapa, os pesquisadores providenciaram o registro da atividade em áudio e consideraram as seguintes condutas:

1. Chamar as crianças pelo nome escrito em seu crachá, de modo a melhor integrá-las ao grupo e a discussão, além de facilitar a análise posterior dos dados a partir do áudio gravado;

2. Propiciar a oportunidade de falar a todos os participantes, solicitando a cada um que acenasse levantando o braço quando desejasse expor algo para o grupo;

3. Anotar os pontos e falas principais durante a discussão;

4. Elaborar perguntas pertinentes à situação que não estivessem presentes no roteiro de discussão previamente estabelecido.

\section{Análise e discussão dos resultados}

Após a realização das etapas de avaliação com o protótipo e com a versão beta do jogo sério digital desenvolvido, destacamos algumas observações apontadas em ambas as etapas:

- Todos os participantes disseram ter contato com desenhos animados e jogos digitais, com maior utilização do desktop, seguido dos dispositivos móveis (smartphone e tablet);

- Dificuldade de leitura e interpretação pelos participantes, acarretando na importância da dublagem de mensagens da interface e falas dos personagens, além da disponibilização do texto escrito;

- Os participantes demonstraram gosto pela música cantada e "tranquila" da animação e pela trilha instrumental e "agitada" do jogo;

- Maior predileção (individualmente e coletivamente) pelo jogo pelos participantes;

- Durante a interação com o jogo, os jogadores apresentaram bastante dificuldade com a utilização do mouse, assim como a alternância entre os periféricos (mouse e teclado) exigida pelo jogo em momentos específicos;

- Durante a interação com o jogo, o nível de imersão apresentado pelos jogadores foi bastante elevado, fazendo-os tolerar o alto nível de dificuldade apresentado em alguns momentos pelo jogo, simplesmente pela vontade de jogar e pelo fator "desafio";

- Predominância de humores positivos durante e após experiência com os objetos da pesquisa (animação e jogo), no teste de medição de humor Pick-A-Mood (PAM); 
- Predominância do fator gênero e cultural nas preferências estéticas dos participantes durante as etapas de entrevista em grupo (grupo focal);

De uma forma geral, após análise e discussão dos resultados pode-se concluir que:

- Na avaliação da animação e protótipo do jogo sério digital, não houve diferenças significativas quanto à retenção do número do SAMU, comparando a animação com o jogo, porém o jogo apresentou-se mais eficaz na preferência dos participantes;

- $\quad \mathrm{Na}$ avaliação da animação e beta do jogo sério digital, não houve diferenças significativas quanto à retenção do número do SAMU, comparando a animação com o jogo, porém o jogo sério digital apresentou maior eficácia na retenção dos sintomas do AVC e na preferência dos pré-adolescentes.

\section{Conclusão e desdobramentos}

No âmbito da Educação, os jogos digitais diferem das demais ferramentas pedagógicas justamente pelo seu caráter interativo e imersivo, contribuindo no processo de construção de conhecimentos de forma ativa, ao envolver e motivar o aluno-aprendiz de forma significativa. Dessa forma, o game design apresenta-se como valioso recurso na projetação para tais experiências, já que por meio do desenvolvimento dos jogos sérios (serious game) torna-se possível combinar a diversão dos jogos digitais com conteúdos e estratégias pedagógicas. Para isso, além da participação integrada dos profissionais da educação dentro de uma equipe multidisciplinar de trabalho, torna-se essencial a inserção do próprio usuário no processo de projetação, participando de forma efetiva e constante das etapas de concepção e avaliação do produto através da adoção do método do Design Centrado no Usuário (DCU).

Sugere-se que como ferramenta ergopedagógica aplicada à Educação em Saúde, o jogo sério digital desenvolvido atendeu as intenções e expectativas dos pesquisadores e usuários, mostrando-se eficaz tanto na motivação e engajamento dos pré-adolescentes, quanto na retenção de conhecimentos que possam ser aplicados em contextos reais da vida dos jogadores-aprendizes. Como desdobramento da pesquisa, o jogo sério digital desenvolvido será disponibilizado gratuitamente na Internet (em versão desktop para os sistemas operacionais Microsoft Windows, Apple Mac OS e Linux) e distribuído fisicamente junto a um kit educativo para professores e alunos de escolas públicas, como em campanhas nacionais de sensibilização e combate ao Acidente Vascular Cerebral (AVC).

\section{Agradecimentos}

Às Pró-Reitorias de Pesquisa, Extensão e Pós-Graduação da UFRN.

Aos membros da equipe de desenvolvimento do jogo "Esquadrão 192": David Lucena de Araújo, Mário Sérgio Filgueira, João Bosco Santos e Raul Henrique da Silva Franco.

Aos pesquisadores colaboradores: André Luis Hernandez Pantoja (UFRN), Antônio Pereira Júnior (UFRN) e Cínthia Costa Kulpa (UFRGS).

À diretora Jeana Magalhães e demais funcionários da Escola Municipal Juvenal Lamartine.

Aos estudantes participantes, seus pais e responsáveis.

\section{Referências}

ALVES, M. M.; BATTAIOLA, A. L. 2014. Design Centrado no Usuário e concepções pedagógicas como guia para o desenvolvimento da animação educacional. Revista Brasileira de Design da Informação, v.11, n.1:21-35.

Anais [Oral] do 7º Congresso Internacional de Design da Informação | CIDI 2015

Proceedings [Oral] of the 7th Information Design International Conference / IDIC 2015 
ALVES, D.; PADOVANI, S. 2006. Estabelecendo Relações entre Critérios de Avaliação Ergonômica em HCl e Recomendações de Game Design. In: Anais do V Simpósio Brasileiro de Games e Entretenimento Digital: SBGAMES. Disponível em: http://sbgames.org/ sbgames06/proceedings/index.htm - acesso 15/03/2015.

BATES, B. 2004. Game Design. 2ed. Boston: Cengage Learning.

BATTAIOLA, A. L. 2000. Jogos por Computador: Histórico, Relevância Tecnológica e Mercadológica, Tendências e Técnicas de Implementação. Anais da XIX Jornada de Atualização em Informática, v. 2, n.1: 83-122.

BATTAIOLA, A. L.; ELIAS; N. C.; DOMINGUES, R. G.; ASSAF, R.; RAMALHO, G. L. 2002. Desenvolvimento de um Software Educacional com base em Conceitos de Jogos de Computador. Anais do XIII Simpósio Brasileiro de Informática na Educação, v.1, n.1: 282-290.

COSTA, L. D. 2010. O que os jogos de entretenimento tem que os educativos não tem: 7 princípios para projetar jogos educativos eficientes. Teresópolis, RJ: Ed. Novas Idéias; Rio de Janeiro: Ed. PUC-Rio.

CSIKSZENTMIHALYI, M. 1999. A descoberta do fluxo. Rio de Janeiro: Rocco.

CSIKSZENTMIHALYI, M.; HUNTER, J. 2003. Happiness in everyday life: the uses of experience sampling. Journal of Happiness Studies, v.4, n.2: 185-199.

DESMET, P.; VASTENBURG, M. V.; VAN BEL, D.; ROMERO, N. 2012. Pick-A-Mood: Development and application of a pictorial mood-reporting instrument. In: Proceedings of 8 International Design and Emotion Conference London 2012. TUDelft - IDStudioLab. < http://studiolab.ide.tudelft.nl/studiolab/pmri/files/2011/08/pick-a-mood-FA.pdf>, 15/03/2015.

GREENFIELD, P. M. 1988. O desenvolvimento do raciocínio na era da eletrônica: os efeitos da TV, computadores e videogames. São Paulo: Summus.

LÉVY, P. Cibercultura. 1999. 3 ed. São Paulo: Editora 34.

PORTUGAL, C. 2013. Design, educação e tecnologia. Rio de Janeiro: Rio Books.

RIBEIRO, L. O. M.; TIMM, M. I.; ZARO, M. A. 2006. Modificações em jogos digitais e seu uso potencial como tecnologia educacional para o ensino de engenharia. Revista Novas Tecnologias na Educação, v.4, n.1: 1-10.

RUBIN, Jeffrey. 1994. Handbook of usability testing. New York: John Willey \& Sons.

SALEN, K.; ZIMMERMAN, E. 2012. Regras do jogo: fundamentos do design de jogos: principais conceitos: volume 1. São Paulo: Blucher.

SANTA ROSA, J. G.; MORAES, A. 2012. Avaliação e projeto no design de interfaces. 1 ed. Teresópolis, Rio de Janeiro: $2 A B$.

SANTA ROSA, J. G.; LIMEIRA, C. F. D.; SANTOS, J. B. M.; FILGUEIRA, M. S. G.; KULPA, C. C.; PINHO, A. L. S.; JÚNIOR, A. P. 2014. Teste de Jogabilidade e Avaliação de um Jogo Digital sobre Sintomas do Acidente Vascular Cerebral e Procedimentos de Emergência. Anais do $11^{\circ}$ Congresso Brasileiro de Pesquisa e Desenvolvimento em Design.

TIMM, M. I.; RIBEIRO, L. O. M.; VIEIRA, V. R. L.; AZEVEDO, A. M.; VIEIRA, E. B. 2008. Game educacional: desafios da integração de elementos ficcionais, tecnológicos, cognitivos e de conteúdo. In: Anais do VII Simpósio Brasileiro de Games e Entretenimento Digital SBGAMES. Disponível em http://www.sbgames.org/papers/sbgames08/gameandculture/ full/gc14 08.pdf - acesso 15/03/2015.

SCHELL, J. 2008. The Art of Game Design: a book of lenses. Burlington: Morgan Kaufmann.

Anais [Oral] do $7^{\circ}$ Congresso Internacional de Design da Informação | CIDI 2015

Proceedings [Oral] of the 7th Information Design International Conference / IDIC 2015 
VENTURELLI, S.; MACIEL, M. L. B. 2008. Imagem interativa. Brasília: Editora Universidade de Brasília.

XAVIER, G. 2010. A condição eletrolúdica: Cultura visual nos jogos eletrônicos. Teresópolis, RJ: Novas Idéias.

YUE, W. S.; ZIN, N. A. M. 2009. Usability Evaluation for History Educational Games. ICIS '09 Proceedings of the 2nd International Conference on Interaction Sciences: Information Technology, Culture and Human, v.1, n.1: 1019-1125.

\section{Sobre os autores}

Carlos Felippe Dias Limeira, mestrando em Design, UFRN, Brasil <carloscafedias@gmail.com> José Guilherme Santa Rosa, D.Sc., UFRN, Brasil <jguilhermesantarosa@gmail.com> André Luís Santos de Pinho, Ph.D., UFRN, Brasil <alsdepinho@gmail.com> 